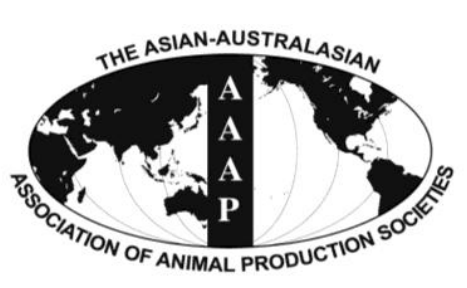

Open Access

Asian Australas. J. Anim. Sci.

Vol. 28, No. 7 : 993-998 July 2015

http://dx.doi.org/10.5713/ajas.14.0847

www.ajas.info

pISSN 1011-2367 elSSN 1976-5517

\title{
Prediction of Eggshell Ultrastructure via Some Non-destructive and Destructive Measurements in Fayoumi Breed
}

\author{
Lamiaa M. Radwan*, A. Galal, and A. R. Shemeis ${ }^{1}$ \\ Department of Poultry Production, Faculty of Agriculture, Ain Shams University, 11241 Cairo, Egypt
}

\begin{abstract}
Possibilities of predicting eggshell ultrastructure from direct non-destructive and destructive measurements were examined using 120 Fayoumi eggs collected from the flock at 45 weeks of age. The non-destructive measurements included weight, length and width of the egg. The destructive measurements were breaking strength and shell thickness. The eggshell ultrastructure traits involved the total thickness of eggshell layer, thickness of palisade layer, cone layer and total score. Prediction of total thickness of eggshell layer based on non-destructive measurements individually or simultaneously was not possible $\left(R^{2}=0.01\right.$ to 0.16$)$. The destructive measurements were far more accurate than the non-destructive in predicting total thickness of eggshell layer. Prediction based on breaking strength alone was more accurate $\left(\mathrm{R}^{2}=0.85\right)$ than that based on shell thickness alone $\left(\mathrm{R}^{2}=0.72\right)$. Adding shell thickness to breaking strength (the best predictor) increased the accuracy of prediction by $5 \%$. The results obtained indicated that both non-destructive and destructive measurements were not useful in predicting the cone layer $\left(\mathrm{R}^{2}\right.$ not exceeded $\left.18 \%\right)$. The maximum accuracy of prediction of total score $\left(\mathrm{R}^{2}=0.48\right)$ was obtained from prediction based on breaking strength alone. Combining shell thicknesses and breaking strength into one equation was no help in improving the accuracy of prediction. (Key Words: Eggshell Ultrastructure, Non-destructive and Destructive Measurements, Prediction Equations, Fayoumi Breed)
\end{abstract}

\section{INTRODUCTION}

As Egyptian local breed, the Fayoumi breed has widely gained reputation among poultry breeders for its favorable growth rate, feed consumption, feed conversion ratio and egg quality attributes (Radwan 2007; Abou El-Ghar et al., 2009; Abou El-Ghar, 2010; Miazi et al., 2011; Rashid et al., 2013).

Eggshell quality was very important in field of poultry industry at either table eggs or hatching domain. Because, the poor eggshell quality causes economic losses due to the distance between the farms and marketing places. On the other hand, the integrity of eggshell and avoiding any cracks are very important for incubation eggs. Few studies have recorded the relationship among some non-destructive and destructive measurements of the eggs of chickens

\footnotetext{
* Corresponding Author: Lamiaa M. Radwan. Tel: +20-2-4441711, Fax: +20-2-4444460, E-mail: Lamia_radwan@agr.asu.edu.eg

${ }^{1}$ Department of Animal Production, Faculty of Agriculture, Ain Shams University, 11241 Cairo, Egypt.

Submitted Nov. 1, 2014; Revised Feb. 1, 2015; Accepted Feb. 9, 2015
}

(Abanikannda et al., 2007; Aygun and Yetisir, 2010), Guinea fowl (Obike and Azu, 2012; Alkan et al., 2013) and quails (Kul and Seker, 2004; Rathert et al., 2011; Ojedapo, 2013). However, no published reports on the use of nondestructive and destructive measurements in constructing prediction equations aiming predicting of eggshell ultrastructure properties of the laying hens.

The aim of this study was to develop prediction equations to predict the total, palisade and cone thickness of eggshell layers from destructive and nondestructive properties instead of the high costs needed to inspect the ultrastructure of eggshell using scanning electron microscope (SEM) technique.

\section{MATERIAL AND METHODS}

This experiment was conducted at Poultry Production Department, Faculty of Agriculture, Ain Shams University. The Fayoumi hens were housed in individual cages from 16 weeks of age up to the end of the experiment at 50 weeks of age. All birds were reared under similar environmental,

Copyright $@ 2015$ by Asian-Australasian Journal of Animal Sciences This is an open-access article distributed under the terms of the Creative Commons Attribution Non-Commercial License (http://creativecommons.org/licenses/by-nc/3.0/), which permits unrestricted non-commercial use, distribution, and reproduction in any medium, provided the original work is properly cited. 
managerial and hygienic conditions. To assess eggshell parameters, a total of 120 Fayoumi eggs at the 45 weeks, were taken. Each egg was weighed and its dimensions (width and length) were measured using a digital caliper to calculate shape index. The thickness $(\mathrm{mm})$ of the shell with intact membranes was measured at three different points in the middle part of the egg using a dial gauge micrometer. Shell breaking strength $(\mathrm{N})$ were measured by quasistatic compression using an Instron (UK527, High Wycombe, Buckinghamshire, UK) fitted with a $50 \mathrm{~N}$ load capture at compression speed of $5 \mathrm{~mm} / \mathrm{min}$. Breaking strength was measured as the maximum force $(\mathrm{N})$ required fracturing each egg.

Samples of eggshell were chosen to investigate thickness layer eggshell (measure effective thickness). The specimens were prepared by cutting a piece $\left(1 \mathrm{~cm}^{2}\right)$ of shell from the equatorial region of each egg. The shell membranes were removed by chemical solution (Radwan, 2007). Following these preparative treatments, two samples from each egg were mounted in inner side uppermost and in vertically manner on aluminum stubs, coated with gold for $3 \mathrm{~min}$ in an Emscope Sputter Coater. These samples were examined using JEOL JSM-T330A scanning electron microscopy at $15 \mathrm{Kv}$. The cross-sectional thickness of palisade and cone layers were directly measured in $\mu \mathrm{m}$ using scaling software provided with the SEM at a magnification of $\times 200$. The total thickness of each specimen was measured as the distance from its' outermost surface to the point where the basal caps inserted into the shell membranes. The thickness of the cone layer was also assessed, this being the distance from the basal caps to the point at which the palisade columns first fused. Subtraction of these two measures provided a thickness of the palisade thickness or effective thickness (Bain, 1990; Solomon, 1991). Triplicate measures were performed in each case and the mean values were used in the statistical analysis. Ultrastructure of eggshell was assessed according to the procedures outlined by Robert and Brackpool (1994).

\section{Statistical analysis}

Data on non-destructive (weight, length and width of egg) and destructive (breaking strength and shell thickness) measurements, as predictors, and the ultrastructure eggshell properties (total, thickness of palisade layer, cone layer and total score), as response variables, were analyzed according to the following regression model of SAS (2005):

$$
\mathrm{Y}_{\mathrm{i}}=\mathrm{a}+\mathrm{b}_{1} \mathrm{X}_{1 \mathrm{i}}+\mathrm{b}_{2} \mathrm{X}_{2 \mathrm{i}}+\ldots+\mathrm{b}_{\mathrm{p}} \mathrm{X}_{\mathrm{pi}}+\mathrm{e}_{\mathrm{i}}
$$

Where:

$\mathrm{Y}_{\mathbf{i}}=$ the dependent variable (ultrastructure eggshell traits) of the $\mathrm{i}^{\text {th }}$ egg;

$$
\mathrm{a}=\text { intercept; }
$$

$\mathrm{X}_{\mathrm{pi}}=$ the $\mathrm{p}^{\text {th }}$ independent variable (non-destructive and destructive traits) of the $i^{\text {th }}$ egg;

$b_{1}, b_{2}, \ldots, b_{P}=$ partial regression coefficients of $Y$ on $\mathrm{X}$ 's; and

$\mathrm{e}_{\mathrm{i}}=$ error assumed to be normally independent distributed with mean $=0$ and variance $=\sigma_{e}^{2}$.

The regression analysis was performed using the REG procedure of SAS (2005).

\section{Detecting multicollinearity}

To indicate multicollinearity, a high degree of correlation among the independent variables, as among the considered predictors in the present study, tolerance value and variance inflation factor value (VIF) were calculated according to Montgomery (2001).

\section{RESULTS AND DISCUSSION}

Means, coefficients of variation and the range for nondestructive, destructive and eggshell ultrastructure are given in Table 1. It appeared that the coefficients of variability for

Table 1. Descriptive statistics for the traits describing non-destructive, destructive and eggshell ultrastructure properties from 120

\begin{tabular}{|c|c|c|c|c|}
\hline Trait & Mean & Coefficient of variation $(\%)$ & Minimum & Maximum \\
\hline \multicolumn{5}{|l|}{ Non-destructive traits } \\
\hline Egg weight (mg) & 50.51 & 6.75 & 43.60 & 55.50 \\
\hline Egg length (mm) & 53.26 & 5.02 & 47.94 & 60.69 \\
\hline Egg width (mm) & 41.17 & 4.84 & 35.09 & 45.89 \\
\hline Shape index $(\%)$ & 77.36 & 3.79 & 70.07 & 82.84 \\
\hline \multicolumn{5}{|l|}{ Destructive traits } \\
\hline Breaking strength $(\mathrm{N})$ & 37.43 & 18.75 & 22.61 & 51.80 \\
\hline Shell thickness (mm) & 0.37 & 11.77 & 0.30 & 0.45 \\
\hline \multicolumn{5}{|l|}{ Structural traits } \\
\hline Total thickness of eggshell layer $(\mu \mathrm{m})$ & 316.96 & 9.92 & 266.00 & 384.00 \\
\hline Palisade $(\mu \mathrm{m})$ & 257.09 & 11.19 & 214.00 & 327.00 \\
\hline Cone $(\mu \mathrm{m})$ & 59.87 & 19.61 & 36.00 & 80.00 \\
\hline Total score (point) & 26.30 & 11.20 & 18.00 & 33.00 \\
\hline
\end{tabular}
Fayoumi eggs 
the traits describing the destructive and ultrastructure of eggshell were comparable (9.92\% to $19.61 \%$ ) and much higher than those for non-destructive properties $(3.79 \%$ to $6.75 \%$ ).

\section{Correlations}

Correlation coefficients between the traits describing the non-destructive, destructive and ultrastructure eggshell properties are given in Table 2.

Weight of the egg (EW) was strongly correlated positively with its length $(0.74$, Table 2$)$. This result is in agreement with the results obtained on different hybrid layers by Abanikannda et al. (2007) (0.73) and Aygun and Yetisir (2010) (0.56), the results given on Guinea fowl by Obike and Azu, (2012) (0.62) and Alkan et al. (2013) (0.57) and the results obtained on quails by Kul and Seker (2004) (0.76) and Rathert et al. (2011) (0.67).

The EW was highly correlated with its width $(0.80$, Table 2; 0.81, Abanikannda et al., 2007; 0.86, Alkan et al., 2013; 0.80, Kul and Seker, 2004; 0.76, Rathert et al., 2011; 0.70, Aygun and Yetisir, 2010; 0.63, Obike and Azu, 2012) and weakly correlated with the shape index $(0.05$, Table 2 ; 0.06, Alkan et al., 2013; 0.12, Aygun and Yetisir, 2010).

Egg length was highly correlated (0.71) with egg width. This value was comparable to the value of 0.77 obtained by Rathert et al. (2011) and much higher than the values of 0.12 to 0.48 obtained by Kul and Seker (2004), Abanikannda et al. (2007), Ojedapo (2013), Alkan et al. (2013), Aygun and Yetisir (2010), and Obike and Azu (2012).

Egg length was negatively correlated with the shape index ( -0.41 , Table 2; -0.59 , Abanikannda et al., 2007; -0.63 , Obike and Azu, 2012; -0.77 , Kul and Seker, 2004; -0.58 , Aygun and Yetisir, 2010; -0.49 , Alkan et al., 2013).
The reason that may be advanced for this negative relationship is the fact that egg length is the denominating factor in estimating shape index according to Panda (1996) and Gunlu et al. (2003). This observation agrees with reports of Choprakarn et al. (1998).

Egg width shows positive correlation with shape index (0.59), this is because shape index in directly related to egg width, and this result is similarly observed by Obike and Azu (2012); Kul and Seker (2004); Rathert at al. (2011) and Aygun and Yetisir (2010). The reason for this could be as a result of the denser part of the egg (yolk) occupying the width area, which translates to heavier weight for the egg.

It seems that the non-destructive traits of the egg (weight, length, width, and shape index) were independent ( $\mathrm{p}>0.05)$ of breaking strength $(\mathrm{r}=-0.28$ to +0.09$)$ and eggshell thickness ( $r=-0.24$ to +0.24$)$.

The eggshell thickness and breaking strength in Fayoumi breed were highly correlated positively $(0.77$, Table 2). This value was much higher than the value of 0.47 obtained on Bandara, Mandarah and Norfa native Egyptian strain as package by Fathi et al. (2010).

Total thickness of eggshell layer was positively correlated with palisade (0.93) and cone (0.40) and negatively with total score of the egg $(r=-0.66$, Table 2; -0.39 , Fathi et al., 2010). The total thickness of eggshell was positively correlated with breaking strength (0.92, Table 2; 0.32, Fathi et al., 2010) and eggshell thickness (0.85, Table 2; 0.50, Fathi et al., 2010).

The traits describing eggshell ultrastructure were weakly correlated $(p>0.05)$ with non-destructive traits of the egg $(r=-0.35$ to +0.24$)$. These results indicated that the non-destructive traits were not useful in predicting the eggshell ultrastructure properties. The strong correlation coefficients obtained between thickness of total and

Table 2. Simple correlation coefficients and their level of significance among the traits describing non-destructive, destructive and egg shell ultrastructure properties

\begin{tabular}{|c|c|c|c|c|c|c|c|c|c|c|c|}
\hline \multirow{2}{*}{ Trait } & & \multicolumn{4}{|c|}{ Non-destructive } & \multicolumn{2}{|c|}{ Destructive } & \multicolumn{4}{|c|}{ Eggshell ultrastructure } \\
\hline & & $\mathrm{X}_{1}$ & $\mathrm{X}_{2}$ & $\mathrm{X}_{3}$ & $\mathrm{X}_{4}$ & $\mathrm{X}_{5}$ & $\mathrm{X}_{6}$ & $\mathrm{X}_{7}$ & $\mathrm{X}_{8}$ & $\mathrm{X}_{9}$ & $\mathrm{X}_{10}$ \\
\hline \multicolumn{12}{|l|}{ Non-destructive traits } \\
\hline Egg weight & $\mathrm{X}_{1}$ & - & & & & & & & & & \\
\hline Egg length & $\mathrm{X}_{2}$ & $0.74 * *$ & - & & & & & & & & \\
\hline Egg width & $\mathrm{X}_{3}$ & $0.80 * *$ & $0.71 * *$ & - & & & & & & & \\
\hline Shape index & $\mathrm{X}_{4}$ & 0.05 & $-0.41 * *$ & $0.35^{*}$ & - & & & & & & \\
\hline \multicolumn{12}{|l|}{ Destructive traits } \\
\hline Breaking strength & $\mathrm{X}_{5}$ & -0.28 & -0.17 & -0.12 & 0.09 & - & & & & & \\
\hline Shell thickness & $\mathrm{X}_{6}$ & -0.22 & -0.24 & -0.07 & 0.24 & $0.77 * *$ & - & & & & \\
\hline \multicolumn{12}{|l|}{ Structural traits } \\
\hline Total thickness & $\mathrm{X}_{7}$ & -0.29 & -0.26 & -0.09 & 0.24 & $0.92 * *$ & $0.85 * *$ & - & & & \\
\hline Palisade & $\mathrm{X}_{8}$ & -0.34 & $-0.35^{*}$ & -0.19 & 0.22 & $0.83 * *$ & $0.80 * *$ & $0.93 * *$ & - & & \\
\hline Cone & $\mathrm{X}_{9}$ & 0.06 & 0.15 & 0.23 & 0.10 & $0.43 * *$ & $0.31 *$ & $0.40 * *$ & 0.03 & - & \\
\hline Total score & $\mathrm{X}_{10}$ & 0.26 & 0.11 & 0.12 & 0.01 & $-0.69 *$ & $-0.55 * *$ & $-0.66 * *$ & $-0.58 *$ & -0.36 & - \\
\hline
\end{tabular}

* Significant at $\mathrm{p}<0.05$; ** Significant at $\mathrm{p}<0.01$. 
palisade layers, as eggshell ultrastructure traits, and breaking strength (0.92 and 0.85 , respectively) and shell thickness ( 0.85 and 0.80 , respectively) indicated the possibility of use the destructive traits as good predictors for eggshell ultrastructure properties.

\section{Multicollinearity}

Values of tolerance and VIF of the predictors are given in Table 3. Tolerance value represents the amount of variability in independent variable that is not explained by other independent variables. The tolerance values indicated that $28 \%$ of the variability in egg weight is not explained by the other predictors. The corresponding figures were $37 \%$ for egg length, $31 \%$ for egg width, $16 \%$ for breaking strength and $15 \%$ for shell thickness. The values of VIF illustrated that $96.43 \%$ of the variance in egg weight could be explained by the other predictors. The corresponding figures were $97.27 \%$ for egg length, $96.80 \%$ for egg width, $93.67 \%$ for breaking strength and $93.34 \%$ for shell thickness. These results indicate that the degree of
Table 3. Diagnoses of multicollinearity among the predictors

\begin{tabular}{lcc}
\hline Predictor & Tolerance value $^{1}$ & Variance inflation value $^{2}$ \\
\hline Egg weight & 0.28 & 3.57 \\
Egg length & 0.37 & 2.73 \\
Egg width & 0.31 & 3.20 \\
Breaking strength & 0.16 & 6.33 \\
Shell thickness & 0.15 & 6.66
\end{tabular}

${ }^{1}$ Tolerance value less than 0.10 indicates collinearity.

${ }^{2}$ VIF value greater than 10 indicates collinearity.

multicollinearity among the four predictors could be negligible. So, these findings can be trusted and applied to other samples.

\section{Prediction equations}

Regression equations of total thickness of eggshell layer on non-destructive (weight, length, and width of the egg) and destructive (breaking strength and eggshell thickness) measurements together with their accuracy of prediction $\left(\mathrm{R}^{2}\right)$ values are given Table 4 .

Table 4. Regression of some ultrastructure egg shell traits on direct non-destructive and destructive measurements

\begin{tabular}{|c|c|c|c|c|c|c|c|c|}
\hline \multirow{2}{*}{$\begin{array}{l}\text { Dependent } \\
\text { variable }\end{array}$} & \multirow{2}{*}{ Equation } & \multirow{2}{*}{ Intercept } & \multicolumn{5}{|c|}{ b-value for } & \multirow{2}{*}{$\mathrm{R}^{2}$} \\
\hline & & & Egg weight & Egg length & Egg width & Breaking strength & Shell thickness & \\
\hline \multirow{7}{*}{$\begin{array}{l}\text { Total thickness } \\
\text { of layer }\end{array}$} & $\mathrm{E}_{1}$ & 383.17 & -1.26 & - & - & - & - & 0.08 \\
\hline & $\mathrm{E}_{2}$ & 383.17 & - & -3.12 & - & - & - & 0.07 \\
\hline & $\mathrm{E}_{3}$ & 483.17 & - & - & -1.43 & - & - & 0.01 \\
\hline & $\mathrm{E}_{4}$ & 270.28 & -2.16 & -2.69 & 7.36 & - & - & 0.16 \\
\hline & $\mathrm{E}_{5}$ & 162.40 & - & - & - & 4.13 & - & 0.85 \\
\hline & $\mathrm{E}_{6}$ & 89.95 & - & - & - & - & 616.40 & 0.72 \\
\hline & $\mathrm{E}_{7}$ & 114.52 & - & - & - & 2.94 & 251.12 & 0.90 \\
\hline \multirow{8}{*}{$\begin{array}{l}\text { Thickness of } \\
\text { palisade layer }\end{array}$} & $\mathrm{E}_{8}$ & 328.03 & -1.35 & - & - & - & - & 0.11 \\
\hline & $\mathrm{E}_{9}$ & 458.63 & - & -3.78 & - & - & - & 0.12 \\
\hline & $\mathrm{E}_{10}$ & 372.61 & - & - & -2.81 & - & - & 0.04 \\
\hline & $\mathrm{E}_{11}$ & 129.30 & -1.45 & -3.23 & 4.47 & - & - & 0.05 \\
\hline & $\mathrm{E}_{12}$ & 129.30 & - & - & - & 3.41 & & 0.69 \\
\hline & $\mathrm{E}_{13}$ & 61.32 & - & - & - & - & 531.56 & 0.64 \\
\hline & $\mathrm{E}_{14}$ & 79.51 & - & - & - & 2.18 & 261.10 & 0.76 \\
\hline & $\mathrm{E}_{15}$ & 190.28 & - & -1.88 & - & 2.20 & 230.75 & 0.79 \\
\hline \multirow{7}{*}{$\begin{array}{c}\text { Thickness of } \\
\text { cone layer }\end{array}$} & $\mathrm{E}_{16}$ & 55.14 & 0.09 & - & - & - & - & 0.01 \\
\hline & $\mathrm{E}_{17}$ & 24.54 & - & 0.66 & - & - & - & 0.02 \\
\hline & $\mathrm{E}_{18}$ & 3.37 & - & - & 1.37 & - & - & 0.05 \\
\hline & $\mathrm{E}_{19}$ & -51.37 & -0.07 & 0.54 & 2.90 & - & - & 0.17 \\
\hline & $\mathrm{E}_{20}$ & 33.10 & - & - & - & 0.72 & - & 0.18 \\
\hline & $\mathrm{E}_{21}$ & 28.62 & - & - & - & - & 84.85 & 0.08 \\
\hline & $\mathrm{E}_{22}$ & 35.00 & - & - & - & 0.76 & -9.98 & 0.18 \\
\hline \multirow[t]{7}{*}{ Total score } & $E_{23}$ & 20.76 & 0.11 & - & - & - & - & 0.07 \\
\hline & $\mathrm{E}_{24}$ & 20.08 & - & 0.12 & - & - & - & 0.01 \\
\hline & $\mathrm{E}_{25}$ & 18.83 & - & - & 0.18 & - & - & 0.02 \\
\hline & $\mathrm{E}_{26}$ & 35.25 & 0.21 & -0.16 & -0.28 & - & - & 0.09 \\
\hline & $\mathrm{E}_{27}$ & 37.19 & - & - & - & -0.29 & - & 0.48 \\
\hline & $\mathrm{E}_{28}$ & 40.25 & - & - & - & - & -37.89 & 0.31 \\
\hline & $\mathrm{E}_{29}$ & 37.99 & - & - & - & -0.27 & -4.20 & 0.48 \\
\hline
\end{tabular}


Prediction of total layers: Prediction of total thickness of eggshell layer based on non-destructive measurements (weight, length, and width of the egg) individually $\left(E_{1}, E_{2}\right.$, and $\left.E_{3}\right)$ or simultaneously $\left(E_{4}\right)$ was not possible $\left(R^{2}=0.01\right.$ to 0.16$)$. This is due to the low correlations between the dependent variable and the three predictors $(r=-0.29$, -0.26 , and -0.09 , respectively). It appeared that the destructive measurements (breaking strength and shell thickness) were far more accurate than the non-destructive in predicting total thickness of eggshell layer. Prediction based on breaking strength alone $\left(\mathrm{E}_{5}\right)$ was more accurate $\left(R^{2}=0.85\right)$ than that based on shell thickness alone $\left(E_{6}\right)\left(R^{2}\right.$ $=0.72$ ). Adding shell thickness to breaking strength (the best predictor) to formulate $\mathrm{E}_{7}$ was useful in increasing the accuracy of prediction $\left(\mathrm{R}^{2}=0.90\right)$. The high accuracy of prediction obtained from these equations were due to the strong relationship between total thickness of eggshell layer and both of breaking strength (0.92) and shell thickness $(0.85)$. The limited improvement in accuracy of prediction obtained from combining shell thickness to breaking strength into one equation was due to the strong correlation (0.77) between the two predictors.

Prediction of palisade layer: It appeared that weight, length and width of the egg together $\left(\mathrm{E}_{11}\right)$ or individually $\left(E_{8}, E_{9}\right.$, and $E_{10}$, respectively) were not efficient in predicting the thickness of palisade layer $\left(\mathrm{R}^{2}=0.04\right.$ to 0.12$)$. The maximum accuracy of prediction $\left(\mathrm{R}^{2}=0.79\right)$ was obtained with the inclusion of length of egg with the two direct destructive measurements into one equation $\left(E_{15}\right)$. Dropping length of egg from this equation to form $\mathrm{E}_{14}$ was associated with slight reduction in accuracy of prediction $\left(\mathrm{R}^{2}=0.76\right)$. Prediction based on breaking strength alone $\left(E_{12}\right)$ would yield higher accuracy $\left(R^{2}=0.69\right)$ than that based on shell thickness alone $\left(\mathrm{R}^{2}=0.64\right)$.

Prediction of cone layer: The results presented in Table 4 indicated that both non-destructive and the destructive measurements were not useful in predicting the cone layer $\left(\mathrm{R}^{2}\right.$ not exceeded $\left.18 \%\right)$. This is due to the weak correlation between cone layer and these predictors (Table 2).

Prediction of total score: The maximum accuracy of prediction $\left(\mathrm{R}^{2}=0.48\right)$ was obtained from prediction based on breaking strength alone $\left(E_{27}\right)$. Adding shell thicknesses to $\mathrm{E}_{27}$ to form $\mathrm{E}_{29}$ not help in moving the accuracy of prediction.

\section{CONCLUSION}

It is not possible to predict ultrastructure properties of the Fayoumi egg from non-destructive measurements. The destructive measurements (breaking strength and shell thickness) individually or together are accurate predictors for total and Palisade layers.

\section{REFERENCES}

Abanikannda, O. T. F., O. Olutogun, A. O. Leigh, and L. A. Ajayi. 2007. Statistical modeling of egg weight and egg dimensions in commercial layers. Int. J. Poult. Sci. 6:59-63.

Abou El-Ghar, R. Sh. 2010. Genetic analyses of generation means for a cross between two local breeds of chickens: IIIinheritance of egg quality in F3 and backcross generations. Egypt. Poult. Sci. 30:763-772.

Abou El-Ghar, R. Sh., H. M. Shalan, H. H. Ghanem, and O. M. Aly. 2009. Egg quality characteristics from some developed strains of chickens and their crosses. Egypt. Poult. Sci. 29: 1173-1186.

Alkan, S., T. Karsli, A. Galiç, and K. Karabağ. 2013. Determination of phenotypic correlations between internal and external quality traits of Guinea Fowl eggs. Kafkas Universitesi Veteriner Fakultesi Dergisi 19:861-867.

Aygun, A. and R. Yetisir. 2010. The relationships among egg quality characteristic of different hybrid layers to forced molting programs with and without feed withdrawal. J. Anim. Vet. Adv. 9:710-715.

Bain, M. M. 1990. Eggshell Strength: A Mechanical/Ultrastructural Evaluation. Ph.D. Thesis, University of Glasgow, Glasgow, UK.

Choprakarn, K., I. Salangam, and K. Janaka. 1998. Laying performance, egg characteristics and egg composition in Thai indigenous hens. J. Natl. Res. Council Thailand 30:1-17.

Fathi, M. M., Y. K. Afifi, and S. A. El-Safty 2010. Utlrastructural diversity of eggshell quality in some Egyptian local breeds of chicken. Egypt. Poult. Sci. 30:813-827.

Gunlu, A., K. Kiriki, O. Celin, and M. Carip. 2003. Some external and internal quality characteristics of patridge (A. graeca) eggs. Food Agric. Environ. 1:197-199.

Kul, S. and I. Seker. 2004. Phenotypic Correlations between some external and internal egg quality traits in the japanese quail (Coturnix coturnix japonica). Int. J. Poult. Sci. 6:400-405.

Miazi, O. F., G. Miah, M. M. Uddin, M. M. Hassan, and M. F. Ahsan. 2011. Effects of environment and genotype for the expression of weight gain of Fayoumi and Sonali chicks. Inter. J. Nat. Sci.1:22-24.

Montgomery, D. 2001. Design and Analysis of Experiments, Fifth Edn. John Wiley and Sons, Inc. New York, NY, USA. 684 p.

Obike, M. O. and K. E. Azu. 2012. Phenotypic correlations among body weight, external and internal egg quality traits of pearl and black strains of guinea fowl in a humid tropical environment. J. Anim. Sci. Adv.10:857-864.

Ojedapo, L. O. 2013. Phenotypic correlation between the external and internal egg quality traits of pharaoh quail reared in derived savanna zone of Nigeria. J. Biol. Agric. Health. 3:8083.

Panda, P. C. 1996. Shape and texture. In: Textbook on Egg and Poultry Technology (Ed. P. C. Panda). Vikas Publishing House Pvt. Ltd., New Delhi, India. p. 57.

Radwan, L. M. 2007. Comparative Study on Ultrastructural Measurements of Eggshell Quality in Some Local Breeds of Chicken Using Modern Techniques. M. Sc. Thesis, Faculty of Agriculture, Ain Shams University, Cairo, Egypt.

Rashid, A., S. H. Khan, G. Abbas, M.Y. Amer, M. J. A. Khan, and N. Iftikhar. 2013. Effect of egg weight on hatchability and 
hatchling weight in Fayoumi, Desi, and crossbred (Rhode Island Red $\times$ Fayoumi) chickens. Vet. World 6:592-595.

Rathert, T. C., F. Uckardes, D. Narinc, and T. Aksoy. 2011. Comparison of principal component regression with the least square method in prediction of internal egg quality characteristics in Japanese quails. Kafkas Univ. Vet. Fak Derg, $17: 687-692$.
Robert, J. R. and C. E. Brackpool. 1994. The ultrastructure of avian eggshells. Poult. Sci. Rev. 5:245-247.

SAS Institute 2005. SAS/STAT User's Guide: Statistics. SAS Institute Inc., Cary, NC, USA.

Solomon, S. E. 1991. Egg and Eggshell Quality. Wolfe Publishing Ltd. London, UK. 